\title{
MECHANICAL AND THERMAL PROPERTIES OF WASTE BIO-POLYMER COMPOUND BY HOT COMPRESSION MOLDING TECHNIQUE
}

\author{
M. Khairul Zaimy A. G. ${ }^{1,}$, Anika Zafiah M. Rus ${ }^{1, b}$, , Najibah Ab Latif ${ }^{1}$ and \\ Nurulsaidatulsyida $\mathbf{S}^{1}$ \\ ${ }^{1}$ Sustainable Polymer Engineering \\ Advanced Manufacturing \& Material Centre (AMMC) \\ Faculty of Mechanical and Manufacturing Engineering \\ Universiti Tun Hussein Onn Malaysia (UTHM) \\ 86400, Parit Raja, Batu Pahat, Johor, Malaysia. \\ Email: "amohdkai86@gmail.com, bafiah@uthm.edu.my, \\ Phone: +60127282205
}

\begin{abstract}
The demand for bio-polymer compound (BPC) has attracted attention in various applications from industrial to medical. Therefore, the mechanical and thermal stability properties of recycling industrial waste BPC are very important to investigate. The waste BPC for this study is based on a mixture of hydroxylated waste cooking oil with hardeners to produce waste bio-polymer foam (WBF). The granulate of WBF was cast into the mold until all spaces were evenly filled and compacted into a homogeneous shape and thickness at 30-45 bar for 2 hours using hot compression molding. This method of BPC fabrication results in a tensile and flexural strength of $4.89 \mathrm{MPa}$ and $18.08 \mathrm{MPa}$ respectively. Meanwhile, the thermal stability of laminated BPC was conducted using a thermal gravimetric analyzer (TGA), and the first degradation of the soft segment occurred at $263^{\circ} \mathrm{C}$, then subsequently the second degradation occurred at $351^{\circ} \mathrm{C}$ and the last at $416^{\circ} \mathrm{C}$.
\end{abstract}

Keywords: bio-polymer compound, hot compression molding, thermal stability.

\section{INTRODUCTION}

Due to environmental and sustainability issues, this century has witnessed remarkable achievements in green technology in the field of materials science through the development of bio-composites or bio-polymer compound (BPC). The development of high-performance materials made from natural resources is increasing worldwide (Faruk, Bledzki, Fink, \& Sain, 2012). Historically, while predominantly aerospace materials, natural fiber-reinforced composite structures have seen increased applications in other industries such as automotive, marine transportation, civil engineering, sporting goods, medical equipment and prosthetic devices. Natural fiber-reinforced composite structures provide high strength, high mechanical stiffness properties, unique flexibility in design capabilities, and ease of fabrication. Also, they are lightweight, corrosionresistant, impact-resistant, and have excellent fatigue strength (Bumpus, 2002). The greatest challenge in working with natural fiber-reinforced plastic composites is the large variation in their properties and characteristics. The properties of bio-composites such as BPC are influenced by a number of variables, including the temperature, pressure applied to molding, processing methods, and type of resin, of which the most popular matrices in bio-composites are based on petrochemicals (Faruk et al., 2012). 
Bio-composites or BPC are composed of two or more materials which, when properly combined, form a different material with properties not available from the ingredients alone. Depending on the ingredients chosen and the method of combining them, a large spectrum of material properties can be achieved. A brittle material can be made more ductile (flexible) by adding a softer material; conversely, a soft material can be made stiffer. Wood is a good example of a bio-composite. The cellulose fibers provide the strength and are held together by the resin. Reinforced concrete is another example. The steel re-bars provide excellent tensile strength and the concrete provides compressive strength and transfers the load between the steel bars. Modern composites or FRP (fiberreinforced polymers, or plastics) are the newest addition to the structural engineer's toolbox. Although the materials have been available for decades, a reduction in cost, combined with newer understanding of the versatility and benefits of the material properties, has allowed composites to move into mainstream construction (Bumpus, 2002; Hardinnawirda \& SitiRabiatull Aisha, 2012; Mohamed \& Atan, 2012).

Malaysia, as one of the largest producers and manufacturers of palm oil products, generates a large amount of palm oil by-products, which can be recycled into bio-monomer. If this bio-monomer is put to good use, in this case as a main material in bio-polymer compound, then it will greatly reduce the cost of high-performance composite (Ahmad, Hilton, Mohd, \& Mohd Noor, 2007). At the same time, it will also reduce the amount of waste generated by the palm oil industry, thus achieving a global aim of sustainable development. Not only does it reduce waste, it also preserves nature by eliminating the need to harvest natural aggregates from natural sources. With the increased use of bio-composite materials, there is a need to conduct a series of tests to predict the mechanical properties and behavior of BPC materials and the structures made of these materials under a variety of loading and environmental conditions. Furthermore, the thermal stability of BPCs has gained considerable attention because of their potential application in a number of areas. Many applications of BPC require materials that can resist a variety of external stresses such as heat or fire. However, BPCs generally have low thermal stability at high temperatures and thermal degradation can begin to occur at processing temperatures above $180^{\circ} \mathrm{C}$, depending on the parameters (Braun, 1981). The study of the decomposition of biopolymers is particularly difficult since they degrade with the formation of various gaseous products and a number of decomposition steps are typically observed in thermal gravimetric analysis (TGA) experiments. The thermal stability of a material is defined by the specific temperature or temperature-time limit within which the material can be used without excessive loss of properties (Chattopadhyay \& Webster, 2009). The main purpose of this study is to evaluate the degree of conversion and to determine the thermal stability of biopolymer by using TGA with temperatures of $25^{\circ} \mathrm{C}-900^{\circ} \mathrm{C}$ at a rate of $10^{\circ} \mathrm{C} / \mathrm{min}$. The exploration of this bio-polymer compound (BPC) from waste palm cooking oil using a hot compression technique is vital to embark on the study of this area. The preliminary study was conducted based on the processing conditions that influence the mechanical and thermal properties of BPC.

\section{EXPERIMENTAL}

\section{Preparation Bio-Foam Compound (BFC)}

Bio-Foam Granulate (BFG) was prepared (Rus, 2009) and cut into small cubes of approximately $10 \mathrm{~mm} \times 10 \mathrm{~mm} \times 10 \mathrm{~mm}$ and grained using a rotor mill to form small 
particles, starting with $6.00 \mathrm{~mm}$, followed by $2.00 \mathrm{~mm}$ and $0.50 \mathrm{~mm}$. These small granules were cast into the mold until all spaces were evenly filled, and then hot compressed into a homogeneous shape and thickness at 30-45 bar and temperature of $40-55^{\circ} \mathrm{C}$ for 2 hours. The sample was laminated with $10 \mathrm{~g}$ of epoxy on the top and bottom on both sides of the BPC.

\section{Characterizations}

The tensile and flexural strength of the BPC was tested using a Universal Testing Machine (UTM) model Lloyd Instruments LR30K according to standard BS EN ISO 527-2:1996 Type 1A, with $1.0 \mathrm{~mm} / \mathrm{min}$ crosshead speed (BS EN ISO, 1996). The flexural (3 point bending test) was in accordance with ISO 178:2010 at a speed of 0.10 $\mathrm{mm} / \mathrm{min}$ (ISO 178, 2010). The specimen dimensions for the tensile test were $150 \mathrm{~mm}$ long, $10 \mathrm{~mm}$ wide and $4.0 \mathrm{~mm}$ thick, while for the flexural test they were $80 \mathrm{~mm}$ long, $10 \mathrm{~mm}$ wide and $4 \mathrm{~mm}$ thick. The Archimedes principle was used to obtain the density of the BFC. A scanning electron microscope (SEM) model JOEL JSM - 6380LA complete with energy-dispersive X-ray spectroscopy (EDX) was used to examine the surface fracture morphology of the tensile specimens. The structure of the specimens was coated with coating conductor material to allow electrons to flow through. The BPC's weight loss as a function of temperature was determined using a Linseis Thermo balance Simultaneous Thermal Analysis (STA) (TG + DTA). For weighing, samples of between 100 and120 $\mathrm{mg}$ were placed in a crucible in a furnace and heated in nitrogen between $25^{\circ} \mathrm{C}$ and $900^{\circ} \mathrm{C}$ at a rate of $10^{\circ} \mathrm{C} / \mathrm{min}$.
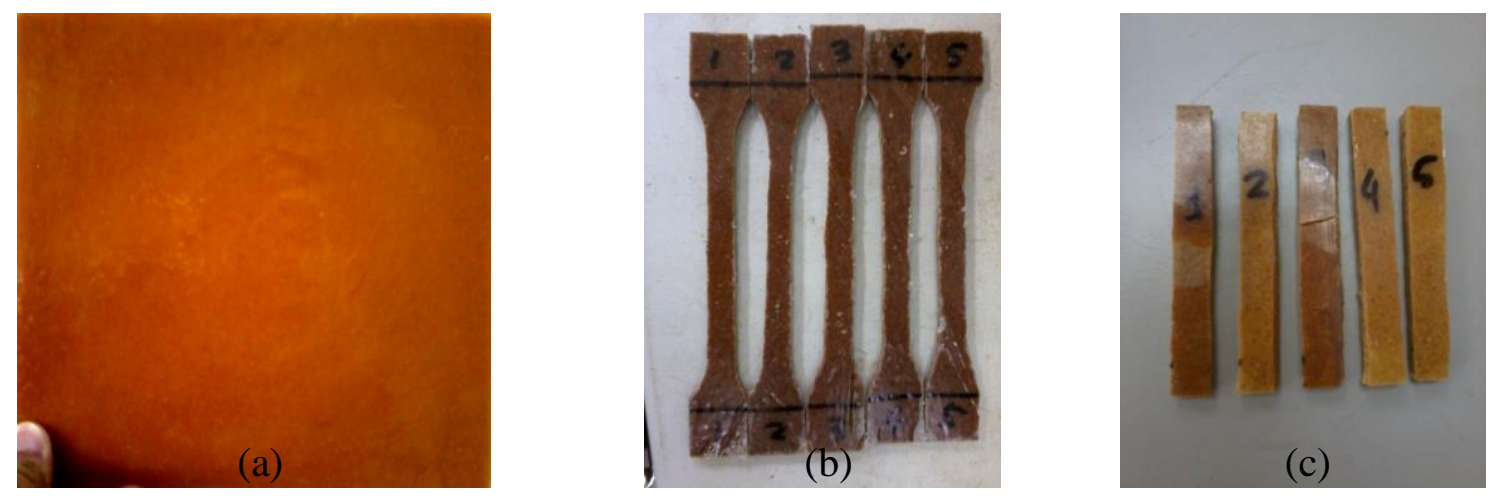

Figure 1. (a) BPC of hot compression moulding; (b) Tensile test specimens;

(c) Flexural strength test specimens

\section{RESULTS AND DISCUSSION}

\section{Mechanical Properties of BPC}

Figure 2 shows the relationship of molding pressure with tensile strength and flexural strength. The tensile strength and the flexural strength of BPC both increase with increased molding pressure. The highest molding pressure revealed the highest tensile strength of $4.89 \mathrm{MPa}$ as well as a flexural strength of $18.08 \mathrm{MPa}$ for both samples of BPC. Meanwhile, the lowest molding pressure of 31 bar revealed the lowest tensile strength and flexural strength of 1.81 and $9.03 \mathrm{MPa}$ of BPC respectively. 


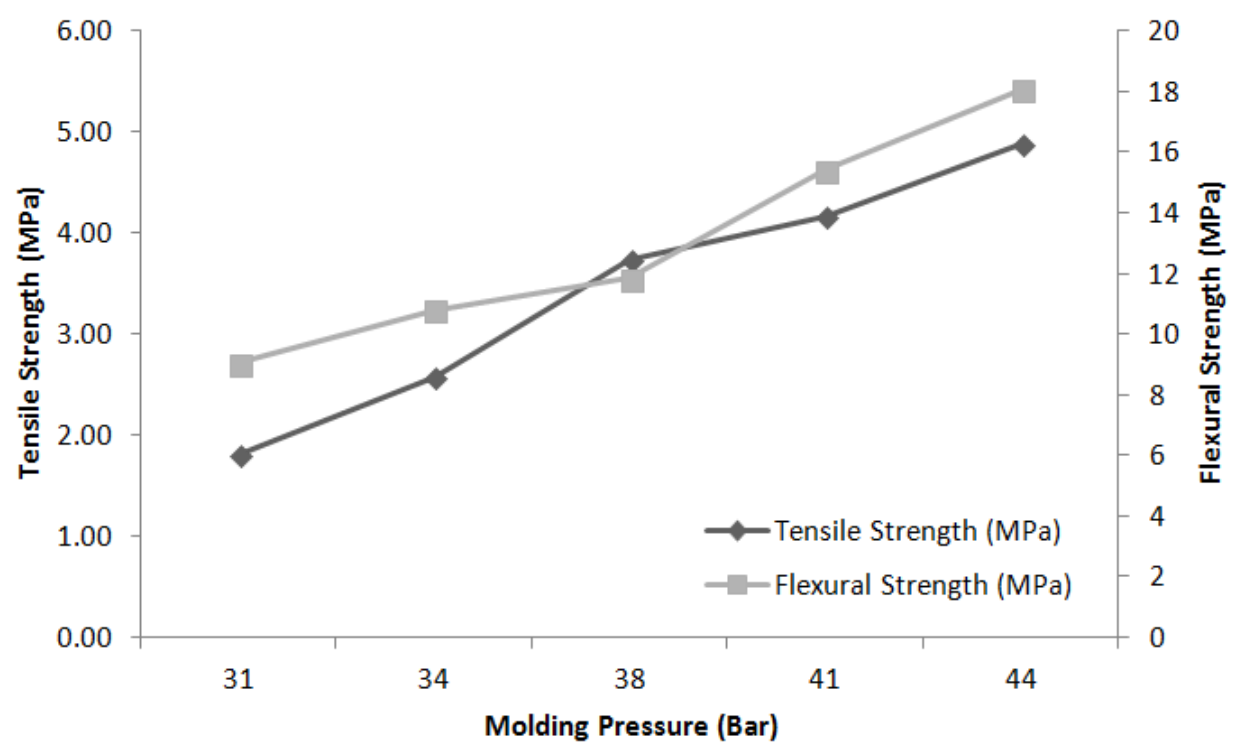

Figure 2. Influence of molding pressure on tensile strength and flexural strength of BPC

Figure 3 presents the relationship between tensile strength and density under increasing molding pressure. By increasing the molding pressure, the density and the tensile strength were increased rapidly. The highest density of 44 bar molding pressure is $1.209 \mathrm{~g} / \mathrm{cm}^{3}$ with the highest tensile strength value of $4.89 \mathrm{MPa}$. This also resulted in a lower tensile value, influenced by the accompanying drop of the density value to $0.857 \mathrm{~g} / \mathrm{cm}^{3}$. Figure 4 depicts the same and systematic pattern as Figures 2 and 3 with the highest flexural strength of $18.08 \mathrm{MPa}$ at $44 \mathrm{bar}$, and $9.03 \mathrm{MPa}$ at the lowest molding pressure of 31 bar.

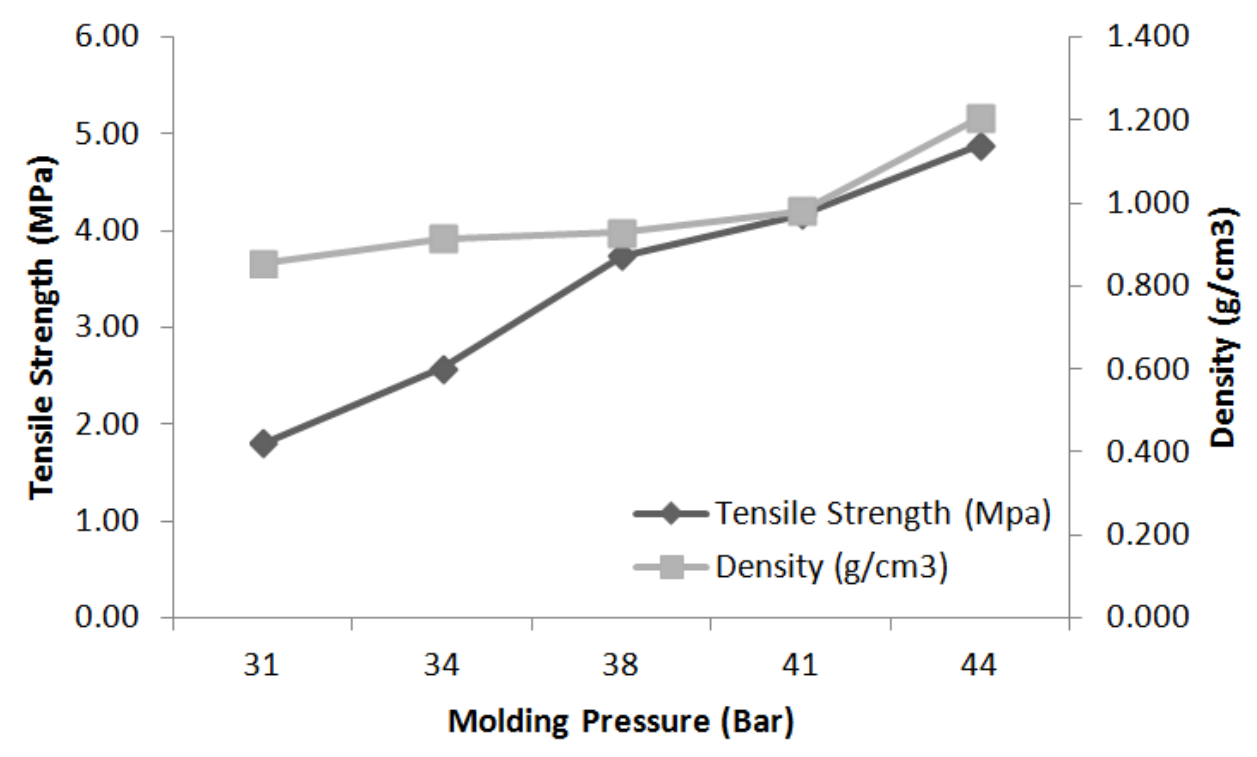

Figure 3. Influence of molding pressure on tensile strength and density of BPC 


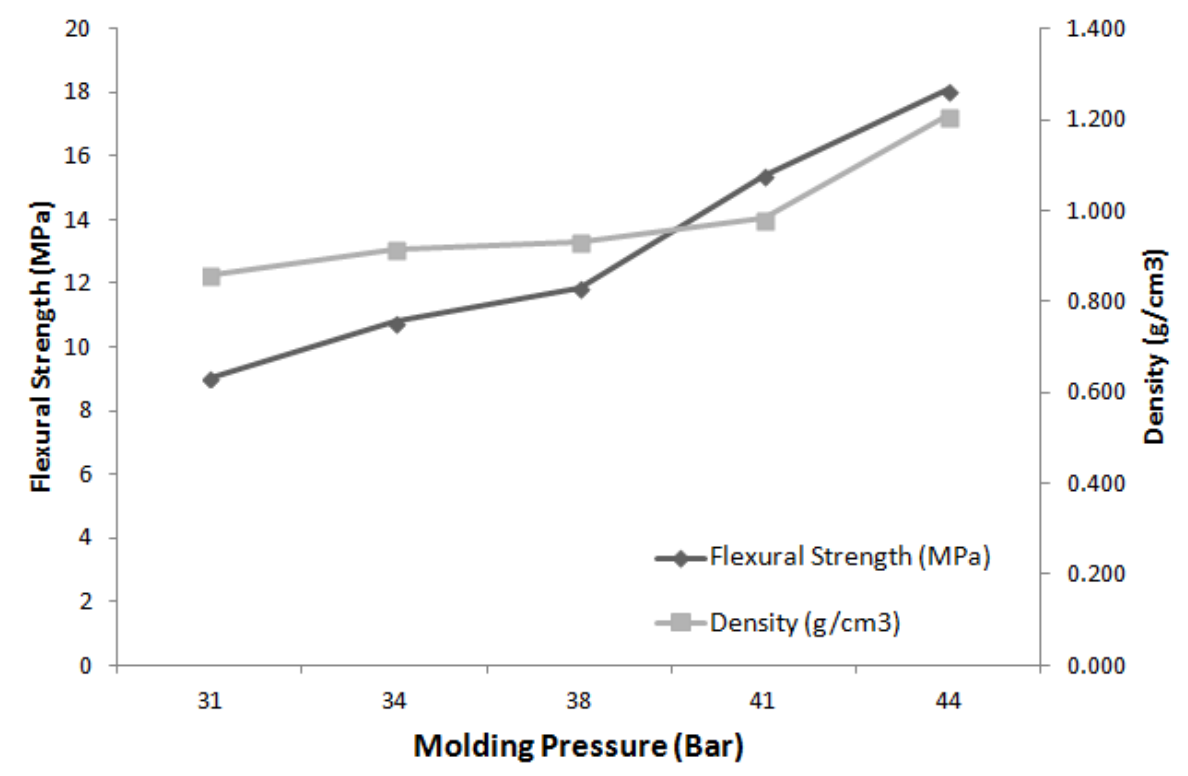

Figure 4. Influence of molding pressure on flexural strength and density of BPC

\section{Morphology Structure of BPC}

The mechanical properties of BPC were affected by internal defects such as voids, as indicated by the surface morphology with black areas. This is in correlation with the findings of (Takagi \& Asano, 2008). Consequently, the density usually serves as a good indicator of the WBC strength, as seen in Figures 3 and 4.

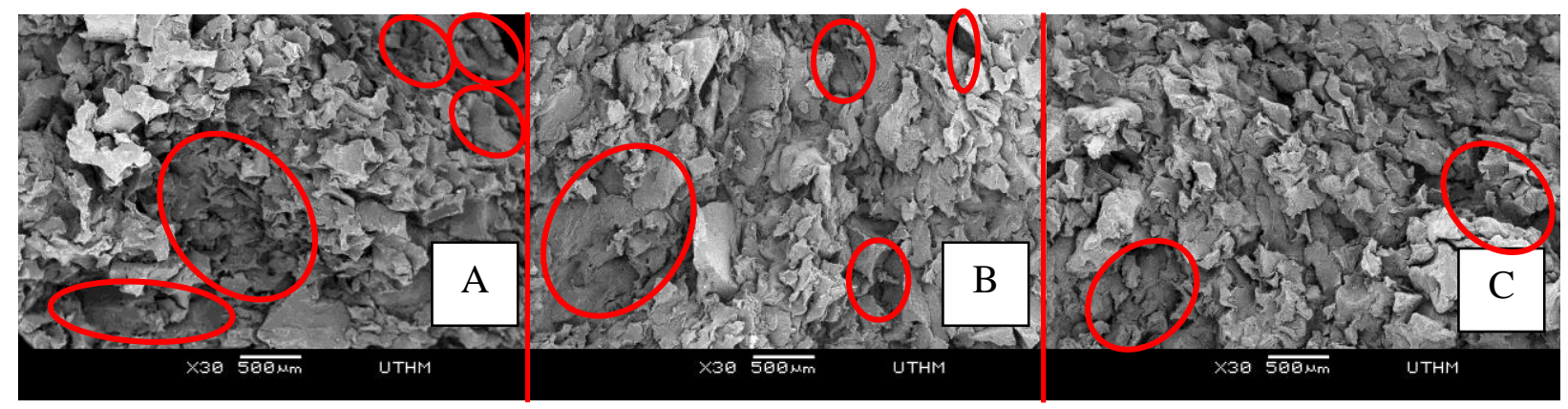

Figure 5. SEM of morphology fracture surface at 30x magnification: (A) molding pressure of 31 bar; (B) molding pressure of 38 bar; (C) molding pressure of 44 bar, with red circles indicating void areas

SEM micrographs of the fractured surface of the laminated BPC are shown in Figure 5. It can be concluded that at low molding pressure (Figure 5(A)) there is debonding of the granulate, leaving holes and voids. The granulate has a tendency to pull out then break, indicating weak adhesion between the granules. At high molding pressure (Figure 5(C)), there are fewer holes and voids due to improvement in the granulate's adhesion. The granulate has covered the holes and void area so there is better stress transfer between the granulate. In addition, the fractured surface also shows granulate breakage rather than pull-out (Annie Paul et al., 2008). This is assumed to be due to increased interfacial shear strength at high molding pressure and good interfacial adhesion between the granulate and epoxy. The SEM pictures prove that the high 
pressure molding setup enhances the mechanical properties of the BPC as compared to low pressure molding. Brittle fracture is observed on the fracture surface of the BPC, and can be identified from the mode of fracture characterized by rapid crack propagation. This type of fracture has a smooth glassy surface that is flat, bright, and shiny, with minimum plastic deformation, as well as percentages of fracture with little yielding before the samples break. Figure 5 shows the brittle fracture of samples (A), (B) and (C) with a minimum strain percentage. The fracture surface for Figure 5 (C) shows voids growing larger, compared with (B) and (A) (Lubarda, 2001).

\section{Thermal Properties of BPC}

The TGA weight loss curve displays 2 or 3 distinct regions that are reflected in the differential weight loss curve. Figure 6 shows that the first curve of the BPC occurs at $74^{\circ} \mathrm{C}$ for volatile material such as gaseous matter (Song, Chen, Yu, Linliu, \& Tseng, 1996) and usually this volatile material is not to be taken as the first decomposition temperature. The first decomposition only occurs on hard segments of $\mathrm{BPC}$ at $260^{\circ} \mathrm{C}$ and continues to $371^{\circ} \mathrm{C}$ for the second decomposition, indicated as the soft segment of the BPC structure. The last decomposition occurs at $415^{\circ} \mathrm{C}$, predicted as the by-product of the hard and soft segment structure. Meanwhile, Figure 7 shows the thermogram of the epoxy material used to laminate the BPC, with hard segment decomposition at $351^{\circ} \mathrm{C}$ and volatile material with 1 distinct region. In Figure 8, the BPC laminated with epoxy shows that the decomposition only started in the hard segment at $263^{\circ} \mathrm{C}$ for the cross-linking agent, the second decomposition occurred at $351^{\circ} \mathrm{C}$ for the epoxy, and the third occurred at $416^{\circ} \mathrm{C}$, according to (Song et al., 1996). The tabulated result of decomposition temperatures is shown in Table 1.

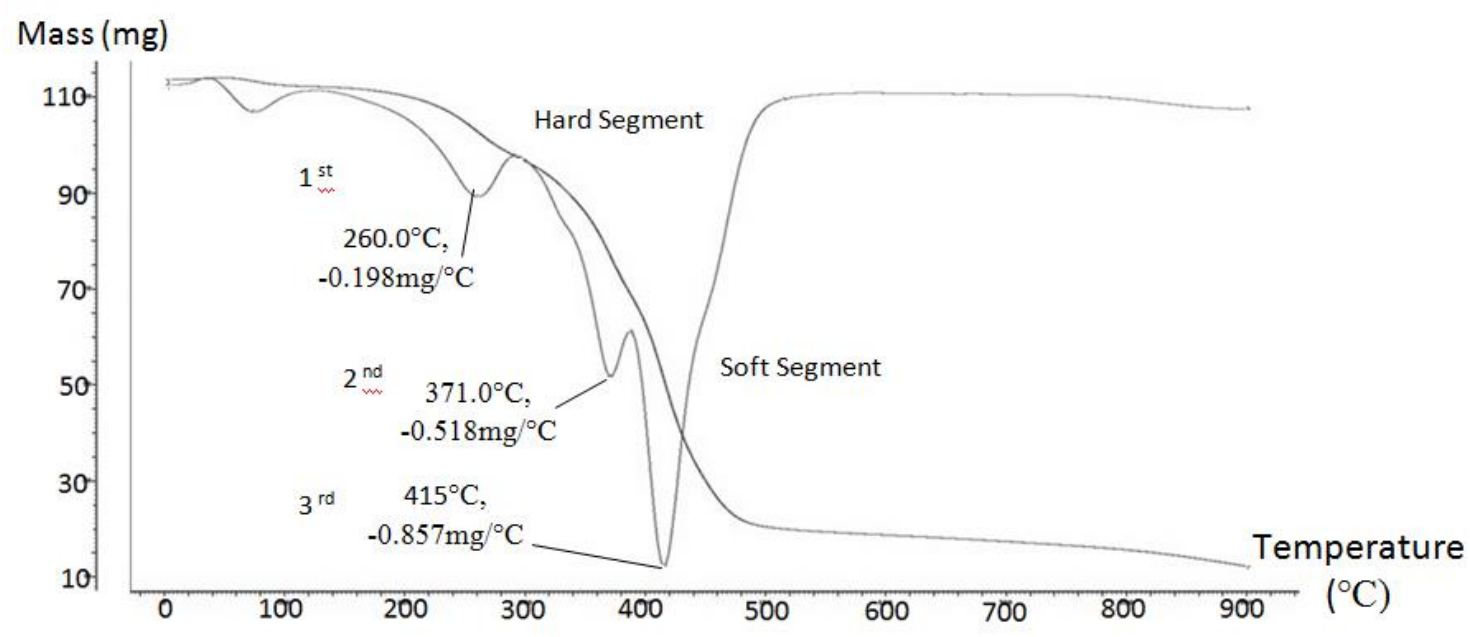

Figure 6. Thermogram of BPC.

Referring to Table 2, the onset degradation temperature, $\mathrm{T}_{\text {on }}$ and maximum temperature, $\mathrm{T}_{\max }$ of the BPC and BPC with laminate consists of a 3-step process. The onset degradation temperature and maximum temperature for the hard segment $\mathrm{T}_{1 \text { on }} \mathrm{T}$ 1 max of the $\mathrm{BPC}$ is $220-280^{\circ} \mathrm{C}$, and for the laminated $\mathrm{BPC}$ it is $230-280^{\circ} \mathrm{C}$. The second $\mathrm{T}_{20 n}-\mathrm{T}_{2 \max }$ for the $\mathrm{BPC}$ is $340-380^{\circ} \mathrm{C}$ and for the laminated $\mathrm{BPC}$ is $330-360^{\circ} \mathrm{C}$, and the last process $\mathrm{T}_{30 n}-\mathrm{T}_{3 \max }$ is $400-455^{\circ} \mathrm{C}$ for the $\mathrm{BPC}$ and $395-460^{\circ} \mathrm{C}$ for the laminated 
BPC of the soft segment. The weight loss of the BPC and laminated BPC during the first degradation is $3.00 \%$ and $1.00 \%$ respectively. The weight losses for BPC and laminated BPC in the second and third stages are $12.00 \%$ and $16.00 \%$ for the second stage, $18.00 \%$ and $23.00 \%$ for third stage. Finally, the remaining weight losses are $67.00 \%$ for BPC and $60.00 \%$ for laminated BPC. The maximum epoxy weight loss occurs at temperature $385^{\circ} \mathrm{C}$ with $68.20 \%$ weight loss.

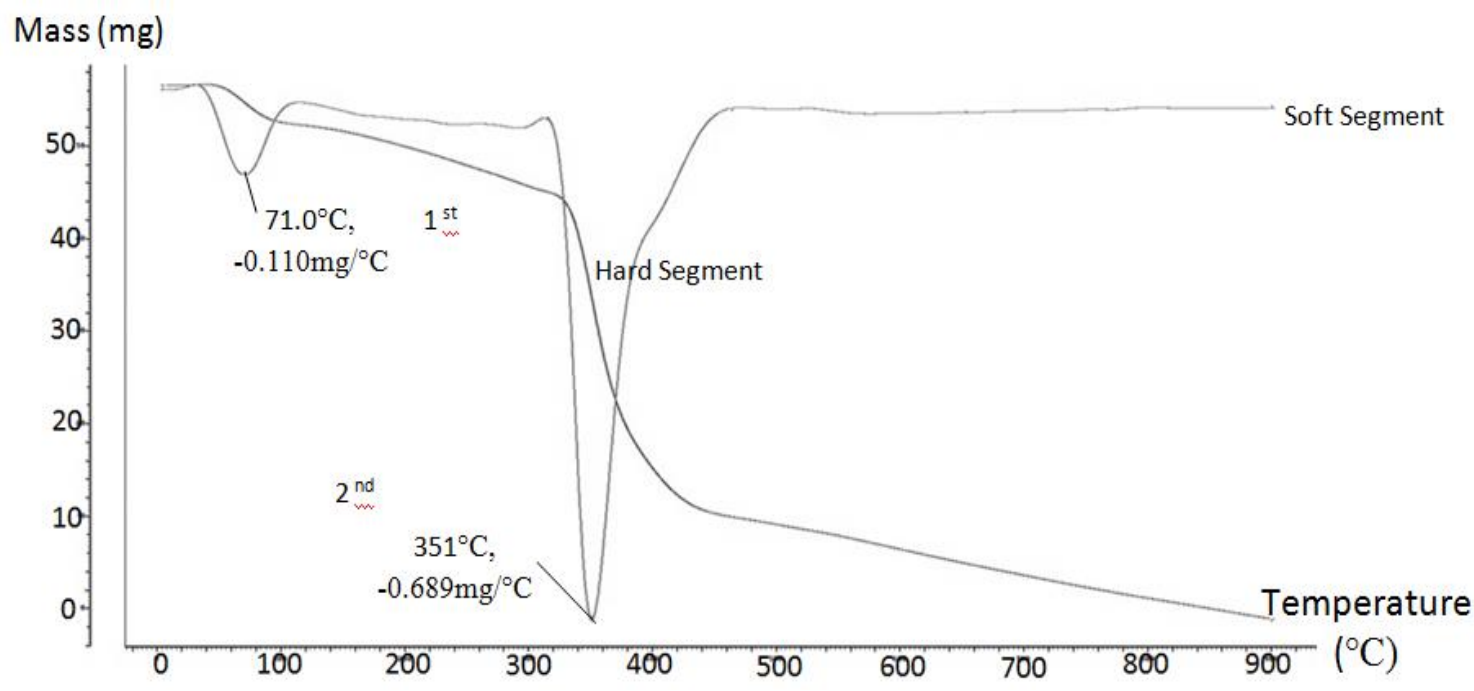

Figure 7. Thermogram of epoxy.

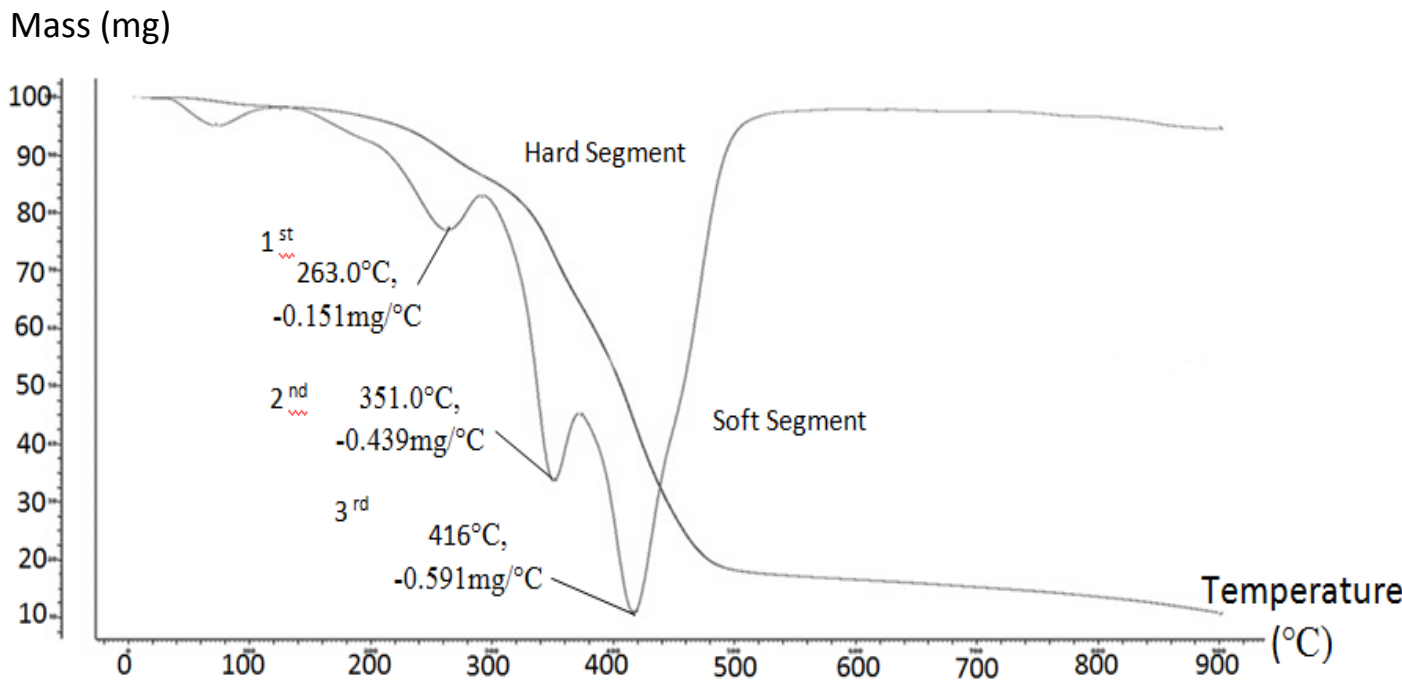

Figure 10. Thermogram of laminated BPC with epoxy.

Table 1. The degradation temperature of the first, second and third decompositions

\begin{tabular}{lccc}
\hline Sample & First $\left({ }^{\circ} \mathrm{C}\right)$ & Second $\left({ }^{\circ} \mathrm{C}\right)$ & Third $\left({ }^{\circ} \mathrm{C}\right)$ \\
\hline BPC & 260 & 371 & 415 \\
Epoxy & 351 & 385 & - \\
BPC laminated with & 263 & 351 & 416 \\
epoxy & & & \\
\hline
\end{tabular}


Table 2. Degradation temperature of hard and soft segments

\begin{tabular}{lcccccc}
\hline Sample & \multicolumn{2}{c}{ Hard } & \multicolumn{5}{c}{ Soft } \\
\cline { 2 - 7 } & $\mathrm{T}_{1 \text { on }}$ & $\mathrm{T}_{1 \max }$ & $\mathrm{T}_{2}$ on & $\mathrm{T}_{2 \max }$ & $\mathrm{T}_{3 \text { on }}$ & $\mathrm{T}_{3 \max }$ \\
BPC & 220 & 280 & 340 & 380 & 400 & 455 \\
Epoxy & 330 & 385 & 385 & 430 & - & - \\
BPC & 230 & 280 & 330 & 360 & 395 & 460 \\
laminated & & & & & & \\
with epoxy & & & & & & \\
\hline
\end{tabular}

Table 3. Percentages of weight loss of BPC, epoxy and laminated BPC with epoxy from TGA

\begin{tabular}{cccc}
\hline Sample & BPC & Epoxy & $\begin{array}{c}\text { BPC } \\
\text { laminated } \\
\text { with epoxy }\end{array}$ \\
\cline { 2 - 4 } & \multicolumn{3}{c}{ Weight percentages (\%) } \\
$1^{\text {st }}$ & 3.00 & 2.00 & 1.00 \\
$2^{\text {nd }}$ & 12.00 & 5.00 & 16.00 \\
$3^{\text {rd }}$ & 18.00 & 10.00 & 23.00 \\
$4^{\text {th }}$ & 67.00 & 83.00 & 60.00 \\
\hline
\end{tabular}

The degree of conversion $(\alpha)$

The alpha value, $(\alpha)$ is calculated using equation:

$$
\alpha=1-w(t) / w_{o}
$$

(Chandra, Singh, \& Gupta)

where:

$\alpha=$ degree of conversion (alpha) $=$ weight loss at given temperature

$w_{o}=$ initial weight

$w(t)=$ weight at any time

$t=$ during degradation

Referring to Table 4, the alpha $(\alpha)$ value of the BPC is 0.09 for the hard segment and 0.22 for the soft segment. The alpha $(\alpha)$ value for laminated BPC is 0.12 at the hard segment and 0.23 during degradation at the soft segment. The value of the degree of conversion for epoxy on the hard segment is 0.42 .

Table 4. Degradation temperature for hard and soft segments

\begin{tabular}{lcc}
\hline Sample & \multicolumn{2}{c}{ Composition Ratio } \\
\cline { 2 - 3 } & Hard & Soft \\
BPC & 0.09 & 0.22 \\
Epoxy & 0.42 & - \\
PBC laminated & 0.12 & 0.23 \\
with epoxy & & \\
\hline
\end{tabular}




\section{CONCLUSION}

The experimental result shows that the mechanical properties such as tensile strength and flexural strength were influenced by the density, void area and molding pressure. In order to improve the compatibility of granulated BPC, more than 45 bar is suggested for the hot compression molding setup. Thus, the tensile and flexural strength of the BPC could be improved. For the thermal properties of the BPC with and without lamination with epoxy, the weight loss shows only a slight difference; for example, at temperature $400^{\circ} \mathrm{C}$ the BPC loss is $48.15 \%$ and laminated $\mathrm{BPC}$ is $48.00 \%$. This demonstrates that lamination with resin (epoxy) does not affect the BPC's decomposition Meanwhile SEM morphology for BPC at high pressure showed fewer voids and less fiber pull-out. This phenomenon indicates that the adhesion between the granulate increases due to good interfacial adhesion between the granules. Furthermore, the maximum tensile strength at the highest compression parameter of pressure is $4.89 \mathrm{MPa}$, with the highest density value.

\section{ACKNOWLEDGEMENT}

The authors would like to thank the Malaysian Government and University Tun Hussein Onn Malaysia (UTHM), Johor for supporting this research under Malaysian Technical University Centre of Excellence (MTUN CoE) research grant Vot C014 and C015, Postgraduate Incentive Research Grant (PIRG) Vot 1122, Johor and the Malaysian Government for supporting this research.

\section{REFERENCES}

Ahmad, H., Hilton, M., Mohd, S., \& Mohd Noor, N. (2007). Mechanical properties of palm oil clinker concrete. Paper presented at the Proceedings of EncOn2007.

Annie Paul, S., Boudenne, A., Ibos, L., Candau, Y., Joseph, K., \& Thomas, S. (2008). Effect of fiber loading and chemical treatments on thermophysical properties of banana fiber/polypropylene commingled composite materials. Composites Part A: Applied Science and Manufacturing, 39(9), 1582-1588.

Braun, D. (1981). Thermal degradation of poly (vinyl chloride). Developments in polymer degradation, 3, 101.

Bumpus, S. R. J. (2002). Experimental setup and testing of fiber reinforced composite structures. (Master), University of Victoria.

Chandra, R., Singh, S. P., \& Gupta, K. (1999). Damping studies in fiber-reinforced composites-a review. Composite Structures, 46(1), 41-51.

Chattopadhyay, D., \& Webster, D. C. (2009). Thermal stability and flame retardancy of polyurethanes. Progress in Polymer Science, 34(10), 1068-1133.

Faruk, O., Bledzki, A. K., Fink, H.-P., \& Sain, M. (2012). Biocomposites reinforced with natural fibers: 2000-2010. Progress in Polymer Science, 37(11), 15521596.

Hardinnawirda, K., \& SitiRabiatull Aisha, I. (2012). Effect of rice husks as filler in polymer matrix composites. Journal of Mechanical Engineering and Sciences, 2, 181-186.

Mohamed, W. A. N. W., \& Atan, R. (2012). Analysis of excessive heating on the thermal and electrical resistance of a polymer electrolyte membrane fuel cell. International Journal of Automotive and Mechanical Engineering, 5, 648-659. 
Rus, A. Z. M. (2009). Material properties of novelty polyurethane based on vegetable oils. Paper presented at the The 11 th International Conference on QiR (Quality in Research), Depok, Indonesia.

Song, Y., Chen, W., Yu, T., Linliu, K., \& Tseng, Y. (1996). Effect of isocyanates on the crystallinity and thermal stability of polyurethanes. Journal of applied polymer science, 62(5), 827-834.

Takagi, H., \& Asano, A. (2008). Effects of processing conditions on flexural properties of cellulose nanofiber reinforced "green" composites. Composites Part A: Applied Science and Manufacturing, 39(4), 685-689. 